\title{
Development of hi-rail vehicle driven on metre-gauge railway/road in Thailand
}

\author{
Viroch Sukontanakarn, Paanthong Sroymuk, Boonlit Pongsatitpat \\ Field of Mechatronics Engineering, Rajamangala University of Technology Isan, KhonKaen, Thailand
}

\begin{abstract}
This research aims to develop a pickup truck to become a hi-rail vehicle that runs on meter gauge railways in Thailand. It is intended to be used for rails maintenance or response times during train derailments and for accessing inaccessible areas via rails in emergency situations. A hi-rail vehicle can travel both on rails and roads. The guide train steel wheels set is designed to have steel wheels running on rails with the vehicle being raised above the rails using a programmable logic controller for hydraulic cylinders. The results of the road test can run at a normal speed of not more than 90 kilometers per hour. The results of the test run on the rails can run at speed of not more than 30 kilometers per hour. There is a vibration of the hi-rail vehicle due to the designed guide train steel wheels set mechanism that can be accepted.
\end{abstract}

This is an open access article under the CC BY-SA license.

Programmable logic controller

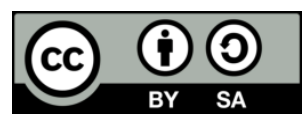

\section{Corresponding Author:}

Viroch Sukontanakarn

Field of Mechatronics Engineering, Rajamangala University of Technology Isan Khonkaen Campus

150 Srichan Road, Khaonkaen 40000, Thailand

Email: viroch.su@rmuti.ac.th

\section{INTRODUCTION}

Nowadays, the use of road-rail vehicles [1] is necessary for continuous rails maintenance systems in many countries such as England, Germany, Japan, China, and other countries. The standard gauge [2] rail has a distance of $1.432 \mathrm{~m}$ between the tracks, which is ideal for placing the wheels on the railways [3] because the distance between the wheels and the rails is the same. Rail inspection vehicle or rail maintenance in foreign countries, also known as road-rail, hi-rail, and hy-rail. It is a pickup truck that can be run on roads and on railway tracks using tire wheels because the distance between the wheels is equal to the distance of rails.

The pick-up truck runs on the rails, a set of train steel wheels is used as guides to force the tire wheels to run on the rails and the hydraulic system is installed to control the lift or drop. In Thailand, meter gauge rails are used with a distance between the rails of $1.0 \mathrm{~m}$. This makes the rubber wheels unable to be placed on the rails because the distance between the rubber wheels is greater than the distance between the track meter gauge.

Therefore, the researcher has designed a device and mechanism to drive the train steel wheels on the meter gauge rail by using hydraulics to lift the car to make the car tire float above the and have a set of extra to support the tire's power. It drives a guide train steel wheels to make the car move, which is a new concept for modifying pickup trucks in Thailand to be used as rail inspection cars, track maintenance, and able to drive in confined areas that cars can't reach if a train accident occurs. It can be used to transport victims to intersections to transport victims to the hospital.

The finite element analysis is the guarantee to design for the mechanical part that has maximum internal stress several safety factors times less than the yield strength of the used steel material to prevent structural failure [4]. The research uses finite element analysis to investigate the guide train steel wheels and axle assembly of hi-rail vehicles under static loads due to rails excitation. Hydraulic control is controlled by a 
programmable logic controller (PLC) and HMI touch screen. The DC-to-DC converter [5] is supplied $24 \mathrm{Vdc}$ to PLC [6] and HMI touch screen. The advantage of guide train steel wheels and axles assembly are used lowcost materials and can be easily installed on any pickup truck in Thailand. When this type of vehicle is discontinued, the device can be removed.

\section{RESEARCH METHOD}

The hi-rail vehicle is a developed pickup truck with including assembly of guide steel wheels set and axles. The next section has proposed the parts of the system is being as:

\subsection{Analysis of the front and rear guide train steel wheels and axles assembly}

The front and rear guide train steel wheels and axles assembly are building geometrical model shown in Figure 1, then bring the model that came analysis of structural strength with finite element analysis [7]-[9]. The design takes into account the selection of parts that have a major impact on the force acting on the vehicle's weight and payload. Some parts of equipment such as brake discs, brake pipes, mounting bolts have been cut off.

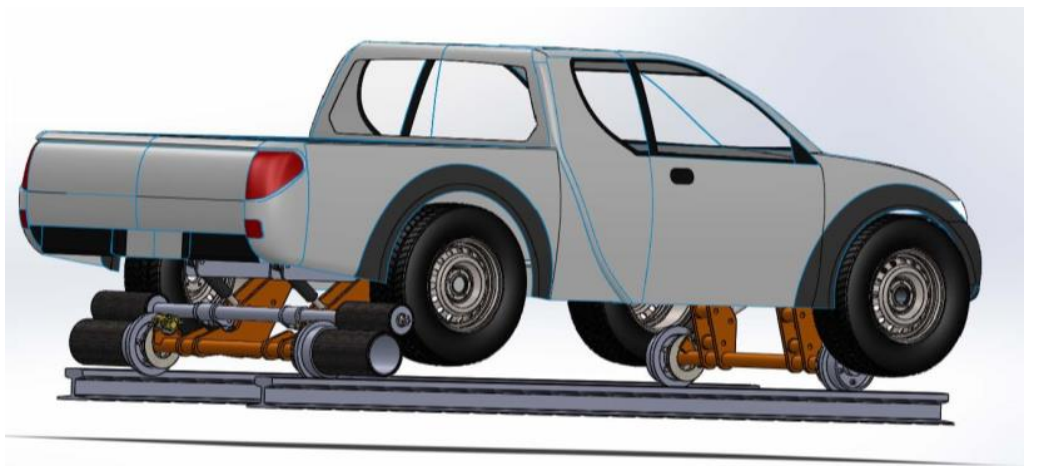

Figure 1.3D drawing of the guide train steel wheels set installed to the prototype pickup truck

Figure 2 shows the geometrical 2D model of all guide train steel wheels assembly. Table 1 shows the numbers of nodes and elements of FEA models are listed. Finite element analysis (FEA) is carried out on ANSYS workbench to catch equipment stress, extreme elastic strain, and whole deformation with the meshed model as shown in Figure 3.

The static excitation force acting on guide train steel wheels assembly is determined from the weight of the vehicle $1,500 \mathrm{~kg}$ and the payload weight of $500 \mathrm{~kg}$. The total is $2,000 \mathrm{~kg}$. The static force is placed at points $\mathrm{A}, \mathrm{B}, \mathrm{C}$, and D. Therefore, each point of load is $500 \mathrm{~kg}$ or approximately 5,000 $\mathrm{N}$ as shown in Figure 4.
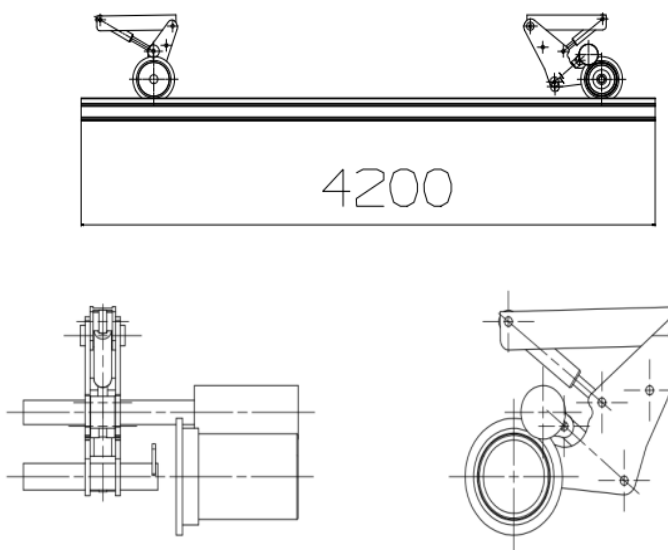

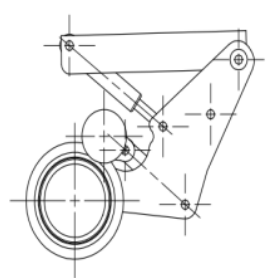

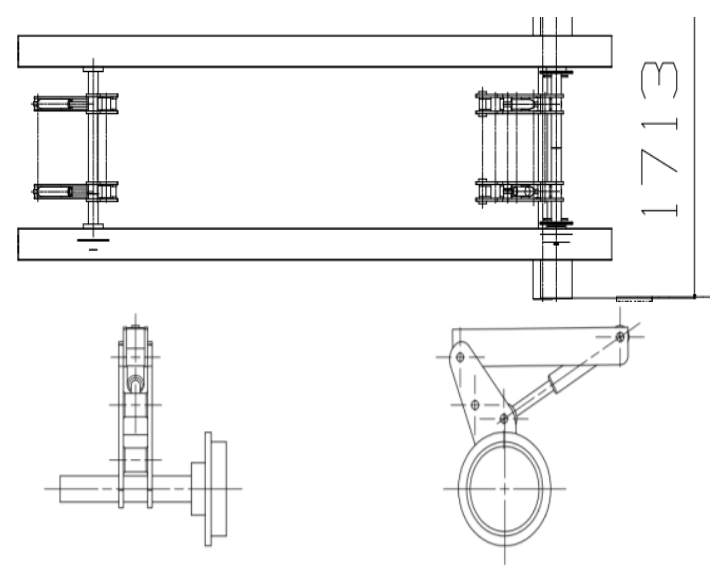

Figure 2. Geometrical model of all guide train steel wheels assembly 
Table 1. Element specification of the FEA models of guide train steel wheels assembly

\begin{tabular}{ccccc} 
& \multicolumn{4}{c}{ Bounding Box } \\
\hline Length X & $4.2024 \mathrm{~m}$ & $0.59383 \mathrm{~m}$ & $0.71428 \mathrm{~m}$ & $4.2024 \mathrm{~m}$ \\
Length Y & $0.18 \mathrm{~m}$ & $1.1005 \mathrm{~m}$ & $1.7214 \mathrm{~m}$ & $0.18 \mathrm{~m}$ \\
Length Z & $0.25153 \mathrm{~m}$ & $0.59006 \mathrm{~m}$ & $0.59625 \mathrm{~m}$ & $0.25153 \mathrm{~m}$ \\
& & Properties & \\
Volume & $3.8094 \times 10^{-2} \mathrm{~m}^{3}$ & $1.9642 \times 10^{-2} \mathrm{~m}^{3}$ & $4.4469 \times 10^{-2} \mathrm{~m}^{3}$ & $3.8094 \times 10^{-2} \mathrm{~m}^{3}$ \\
Mass & $299.04 \mathrm{~kg}$ & $154.19 \mathrm{~kg}$ & $349.08 \mathrm{~kg}$ & $299.04 \mathrm{~kg}$ \\
Centroid X & $3.6398 \mathrm{~m}$ & $5.2344 \mathrm{~m}$ & $2.0463 \mathrm{~m}$ & $3.6398 \mathrm{~m}$ \\
Centroid Y & $1.0898 \mathrm{~m}$ & $1.6395 \mathrm{~m}$ & $2.1892 \mathrm{~m}$ \\
Centroid Z & $1.1743 \mathrm{~m}$ & $1.5628 \mathrm{~m}$ & $1.4597 \mathrm{~m}$ & $1.1743 \mathrm{~m}$ \\
Moment of Inertia Ip1 & $1.2322 \mathrm{~kg} \cdot \mathrm{m}^{2}$ & $25.388 \mathrm{~kg} \cdot \mathrm{m}^{2}$ & $92.688 \mathrm{~kg} \cdot \mathrm{m}^{2}$ & $1.2322 \mathrm{~kg} \cdot \mathrm{m}^{2}$ \\
Moment of Inertia Ip2 & $439.39 \mathrm{~kg} \cdot \mathrm{m}^{2}$ & $6.5884 \mathrm{~kg} \cdot \mathrm{m}^{2}$ & $13.853 \mathrm{~kg} \cdot \mathrm{m}^{2}$ & $439.39 \mathrm{~kg} \cdot \mathrm{m}^{2}$ \\
Moment of Inertia Ip3 & $438.8 \mathrm{~kg} \cdot \mathrm{m}^{2}$ & $21.909 \mathrm{~kg} \cdot \mathrm{m}^{2}$ & $100.33 \mathrm{~kg} \cdot \mathrm{m}^{2}$ & $438.8 \mathrm{~kg} \cdot \mathrm{m}^{2}$ \\
& & Statistics & & \\
Nodes & 465743 & 1200004 & 2883103 & 468884 \\
Elements & 275643 & 709257 & 1835247 & 278031 \\
\hline
\end{tabular}

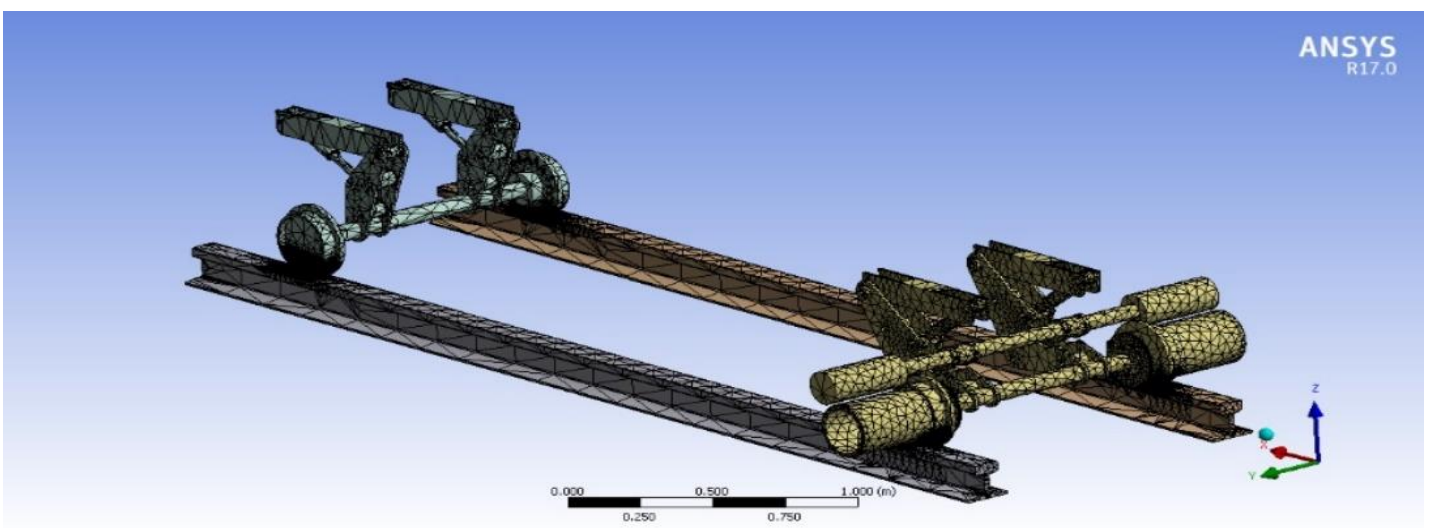

Figure 3. Image of mesh on model

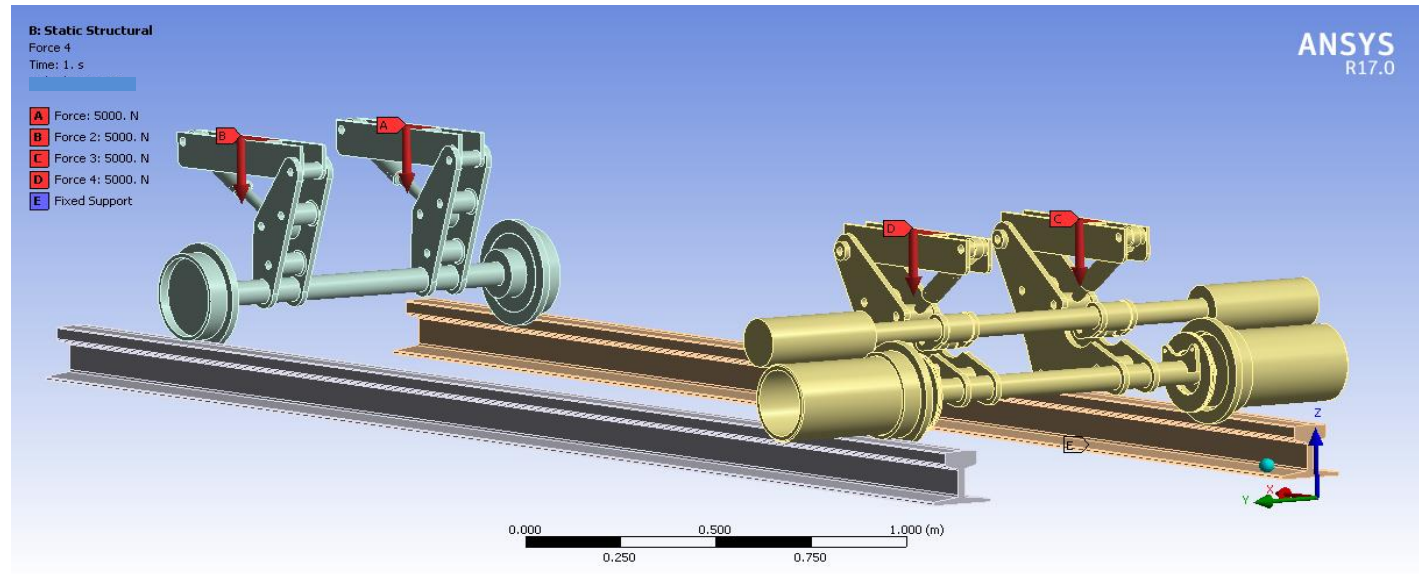

Figure 4. Static excitation force acting on the guide train steel wheels assembly

The results were obtained from the simulation [10]. The stress that occurs will have the force acting on all four steel wheels, with the front train steel wheels having the maximum force acting on the front axle beam and at the point of contact of the steel rails with the rails. The rear steel rails are pressurized on the lower crossbar and the maximum compression is obtained at the steel rails contact to the rails. The result of the equivalent stress [11] is shown in Figure 5. As illustrated in Figure 6, the total deformation of the rear guide train steel wheels and axles model is symmetrical on both wheels (left-right), with the maximum deformation value of the structure being $0.0092 \mathrm{~m}$ or approximately $9.2 \mathrm{~mm}$. The property of material steel st 37 for the construction of guide train steel wheels and axles are shown in Table 2. 


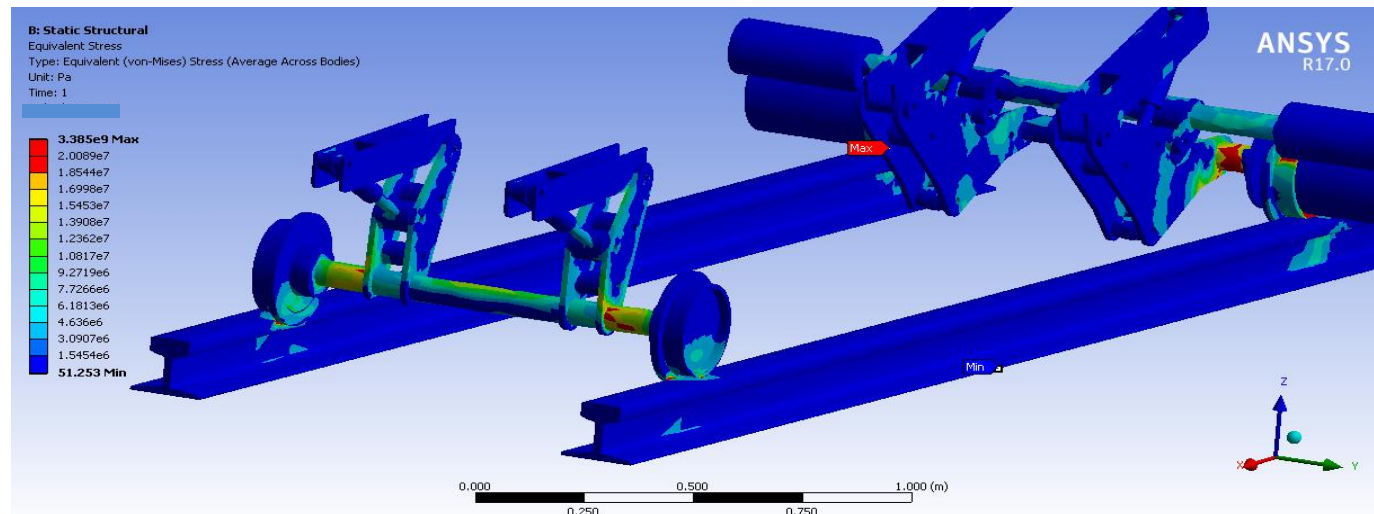

Figure 5. Equivalent stress of front and rear guide train steel wheels and axles model

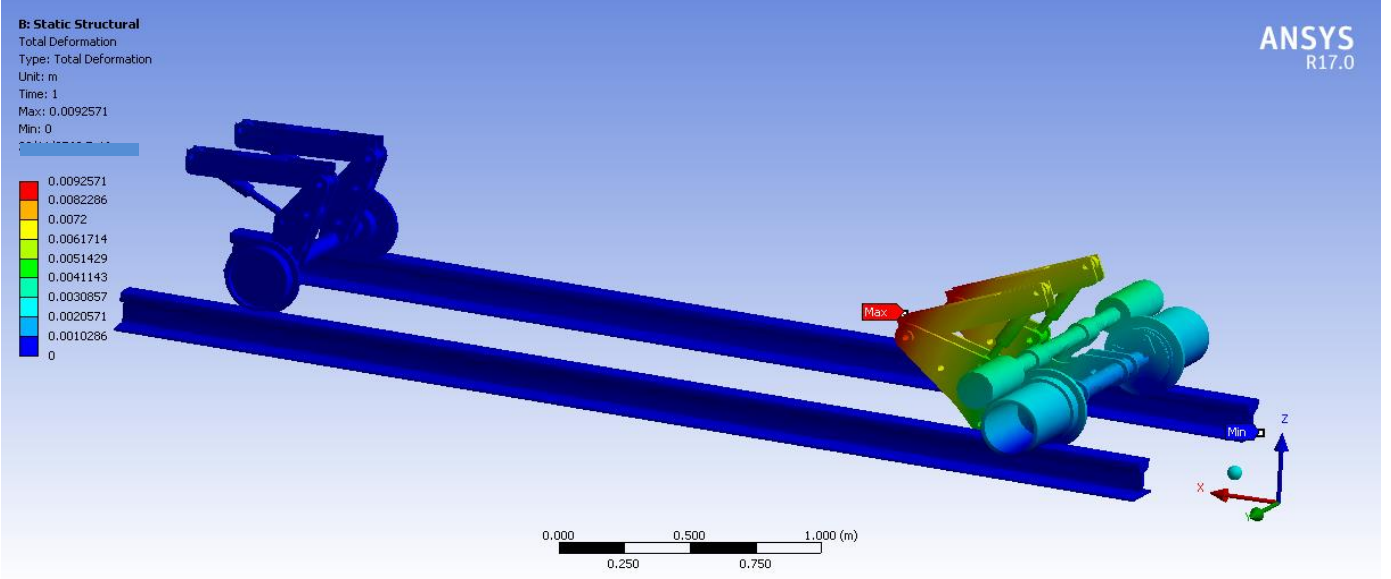

Figure 6. Total deformation of rear guide train steel wheels and axles model

Table 2. Properties of structural steel st 37

\begin{tabular}{lc}
\hline \multicolumn{1}{c}{ Detail } & Units \\
\hline Density & $7,850 \mathrm{~kg} / \mathrm{m}^{3}$ \\
Coefficient of thermal expansion & $1.2 \times 10^{-5} \mathrm{C}^{-1}$ \\
Specific heat & $434 \mathrm{~J} / \mathrm{C}$ \\
Thermal conductivity & $60.5 \mathrm{~W} / \mathrm{m} \mathrm{C}$ \\
Resistivity & $1.7 \times 10^{-7} \mathrm{oh} \mathrm{m}$ \\
Compressive yield strength $\mathrm{Pa}$ & $2.5 \times 10^{8}$ \\
Tensile yield strength Pa & $2.5 \times 10$ \\
Young's modulus Pa & $2.1 \times 10^{11}$ \\
Poisson's ratio & 0.3 \\
\hline
\end{tabular}

The simulation results of material can withstand the loading conditions applied and have less than deformation. The steel density is about $7,850 \mathrm{~kg} / \mathrm{m}^{3}$. The young's modulus for steel is $210,000 \mathrm{Mpa}$. That is so high young's modulus that changes its shape slightly under elastic load. The poisson's ratio is 0.3 that the material has less deformation.

\subsection{Design of mechanical part}

The following is a description of the mechanical system proposed design.

\subsubsection{Specification of hydraulic pump and cylinder}

Consider choosing a $12 \mathrm{Vdc} 1.6 \mathrm{~kW}$ hydraulic pump [12], [13]. The pump kit is an assembly with two double-acting valves to control double-acting hydraulic cylinders [14] in the front and rear cylinders. Specification of hydraulic pump set and hydraulic cylinder are shown in Table 3. 
Table 3. Specification of hydraulic pump and hydraulic cylinder

\begin{tabular}{lc}
\multicolumn{1}{c}{ Detail } & Units \\
\hline Hydraulic pump & \\
DC motor & $12 \mathrm{~V} 1.6 \mathrm{~kW}$ \\
Gear pump & $1.6 \mathrm{cc} / \mathrm{rev}$ \\
Tank capacity & 8 liters \\
Modular block for solenoid valve & $2 \mathrm{ea}$ \\
Solenoid valve DC $12 \mathrm{~V}: 3 \mathrm{C} 2$ & $2 \mathrm{ea}$ \\
Pressure gauge & $0-250 \mathrm{~kg} / \mathrm{cm}^{2}$ \\
Hydraulic cylinder & \\
Bore & $50 \times 35 \times 500 \mathrm{~mm}$ \\
Barrel & $50 \times 60 \mathrm{~mm}$ \\
Rod & $35 \mathrm{~mm}$ \\
Stroke & $500 \mathrm{~mm}$ \\
\hline
\end{tabular}

Figure 7 is shown installing of a hydraulic pump and hydraulic cylinder at the front of the vehicle. The hydraulic pump set is placed on a thick steel base, that is attached to the chassis. Then, connect the hydraulic pipelines from the solenoid valve to the front and rear hydraulic cylinders.

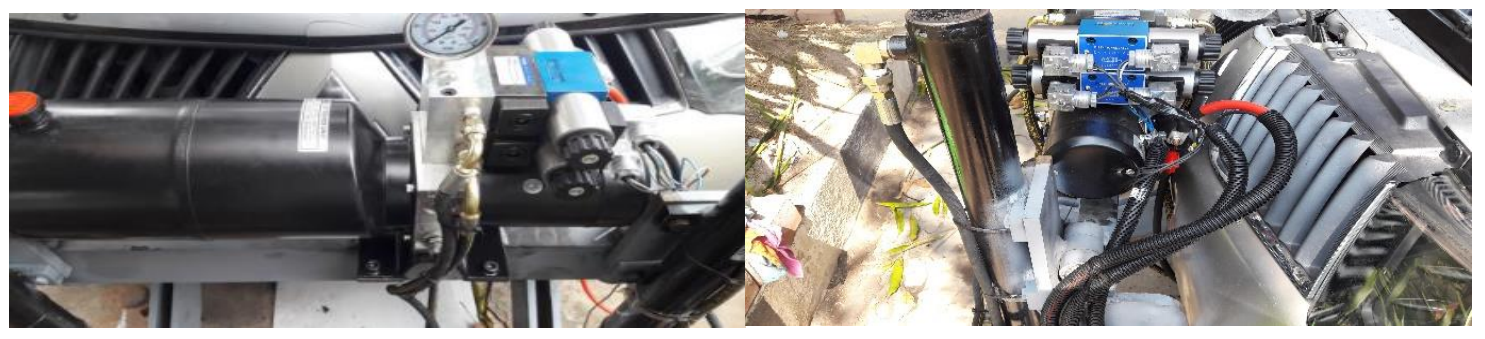

Figure 7. Installed hydraulic pump at the front of vehicle

\subsubsection{Operation of front and rear guide rails steel and axles sets}

The operation of the rear train steel wheels drives when the steel wheels are put down on the rails is controlled by the hydraulic cylinders with a programmable logic controller. When the vehicle is driven forward that the direction of tire wheels will rotate clockwise. The auxiliary tire wheels rotate in a counter-clockwise direction and finally make the train steel wheels turn in the same direction as the tire wheels. Finally, it makes the train steel wheels turn in the same direction as the tire wheels. shown in Figure 8.

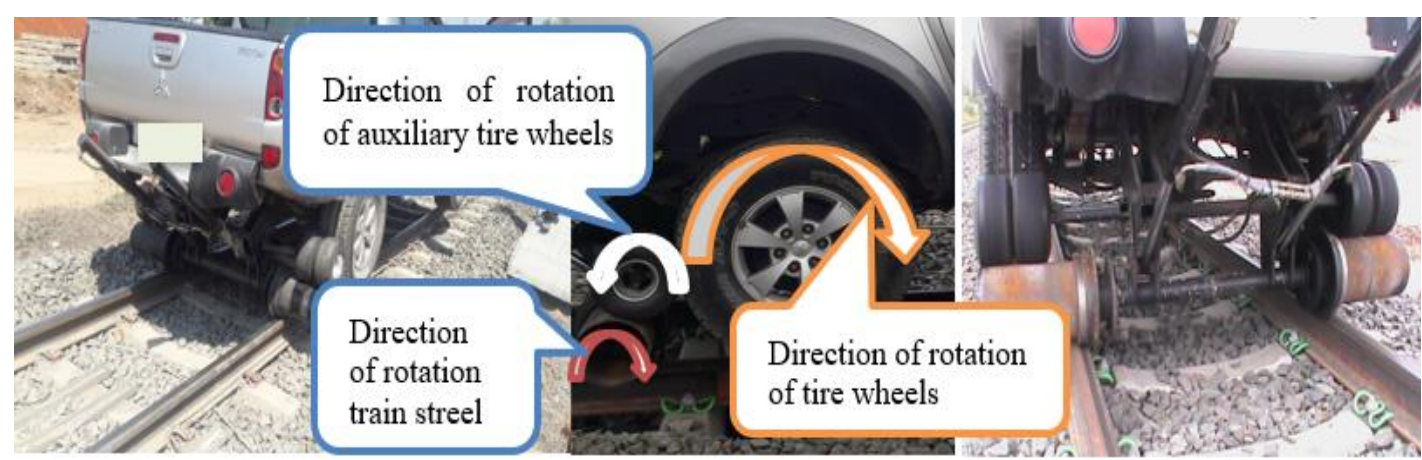

Figure 8. Train steel wheels put down on the rails

\subsection{Design of electrical and PLC control}

The programmable logic control programmable [15]-[18] is programmed to control the electric hydraulic pump and 4/3 direction control valves for the front and backside cylinders. The system can operate by pressing a button on the touch screen inside the car or using a mobile phone from outside. The vehicle is equipped with an application written in the MIT inventor program [19], [20]. The Arduino Uno board and hc05 bluetooth [21] modules will receive signals from mobile phones and send the control signals to PLC input with the relay module. Figure 9 is shown the overall architecture of the hi-rail vehicle control system and 
installing of the HMI touch screen [22], mobile phone with an application android control program. Inside the cabin is equipped with a control screen, emergency switches that can control the hydraulic system [23] from the inside. The mobile application [24] can be used to control the lifting of the rail steel place on the rails from outside the car as shown in Figure 10.

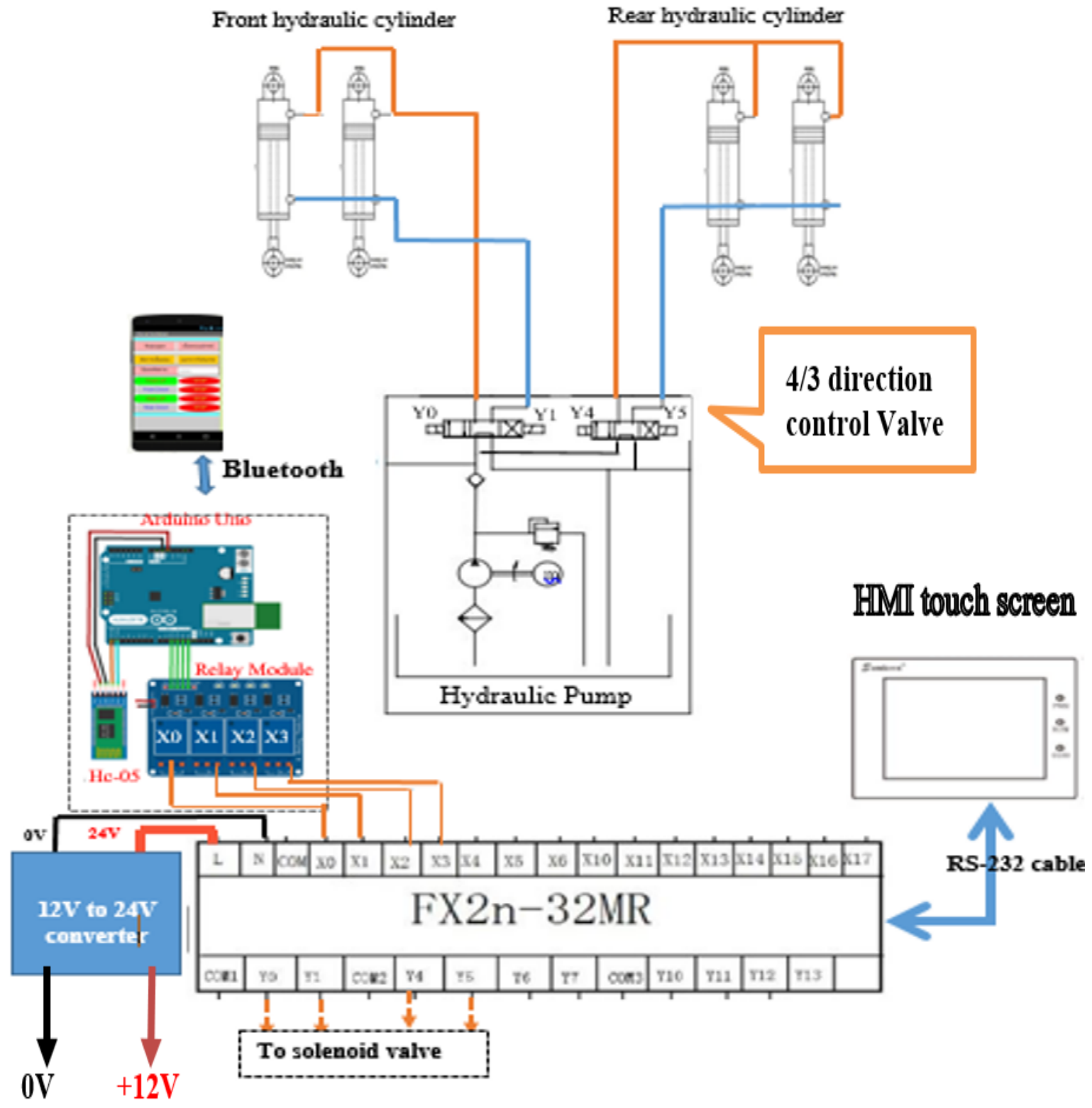

Figure 9. Overall architecture of hi-rail vehicle control system
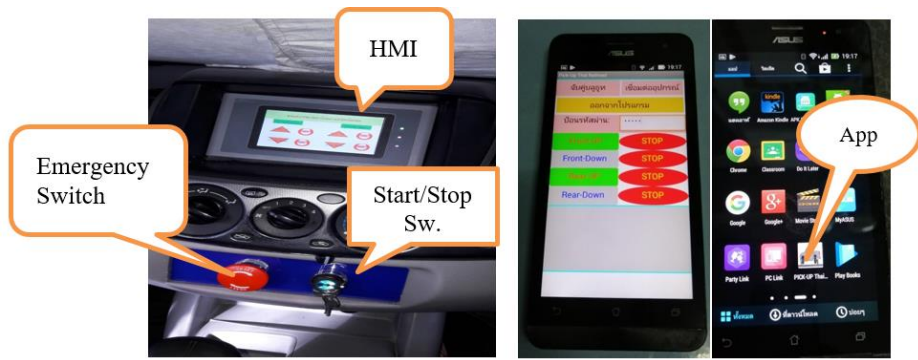

Figure 10. HMI and application mobile phone control 


\section{RESULTS AND ANALYSIS}

To evaluate the performance of mechanical design, the hardware and software are completed on a hirail vehicle. We conduct a real test by running hi-rail vehicles on a road and rails is being as:

\subsection{Road test results}

The researcher drove this hi-rail vehicle from Rajamangala University of Technology Isan Khon Kaen Campus along with the Mittraphap road station to the test point of the Tha Phra-Khon Kaen railway line at a speed less than $90 \mathrm{~km} / \mathrm{hr}$ and recorded by a GPS Speed application [25] as shown in Figure 11.

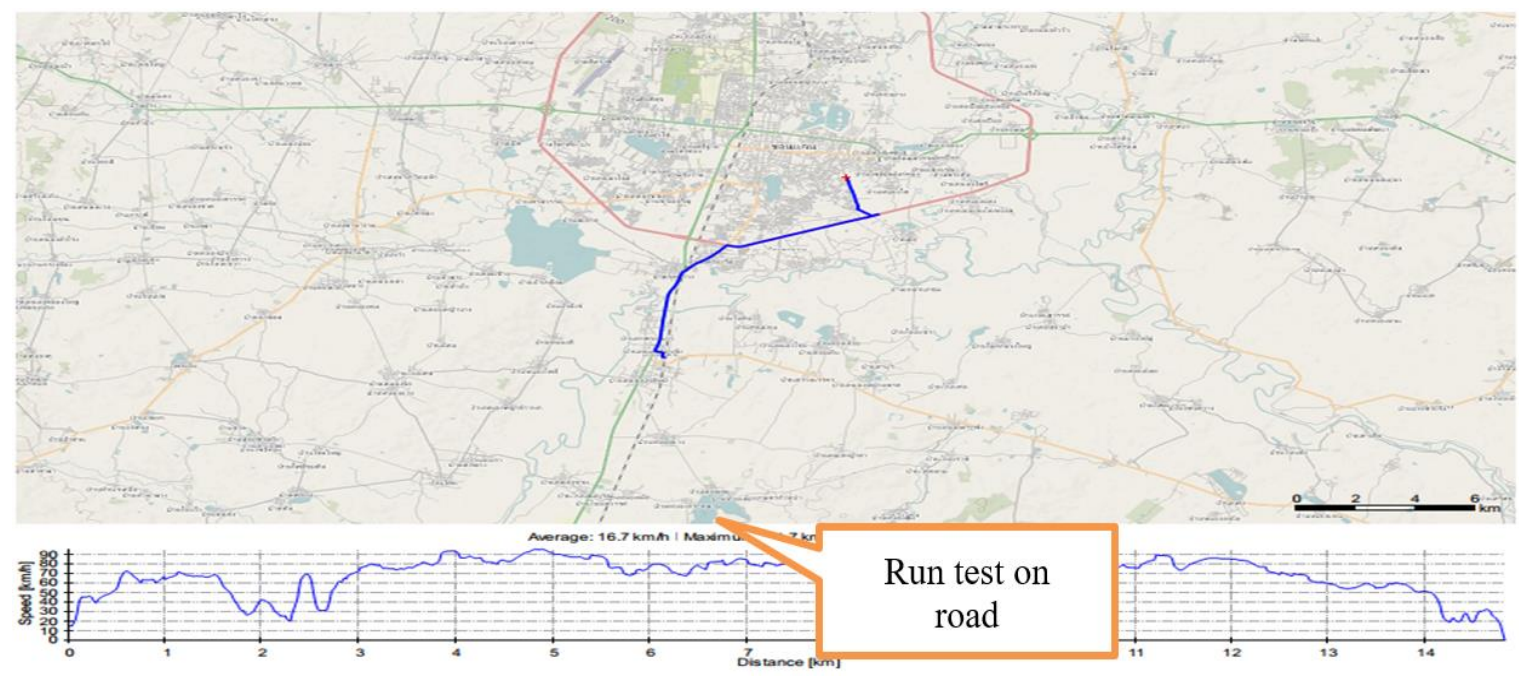

Figure 11. Show recorded routes and speed ranges of cars on the road through the GPS speed application

\subsection{Rail test results}

When running on a concrete road, arrive at the test track. Then place both steel wheels front and rear on rail tracks and drive the vehicle at a test speed of not more than $30 \mathrm{~km} / \mathrm{hr}$ in both forward and reverse directions as shown in Figure 12. The GPS position track of the driving on rails was shown in Figure 13. The testing and demonstration of the running on the real track by run-up for a real test on the railroad tracks at Tha Phra Station, Mueang District, Khon Kaen Province as shown in Figure 14.

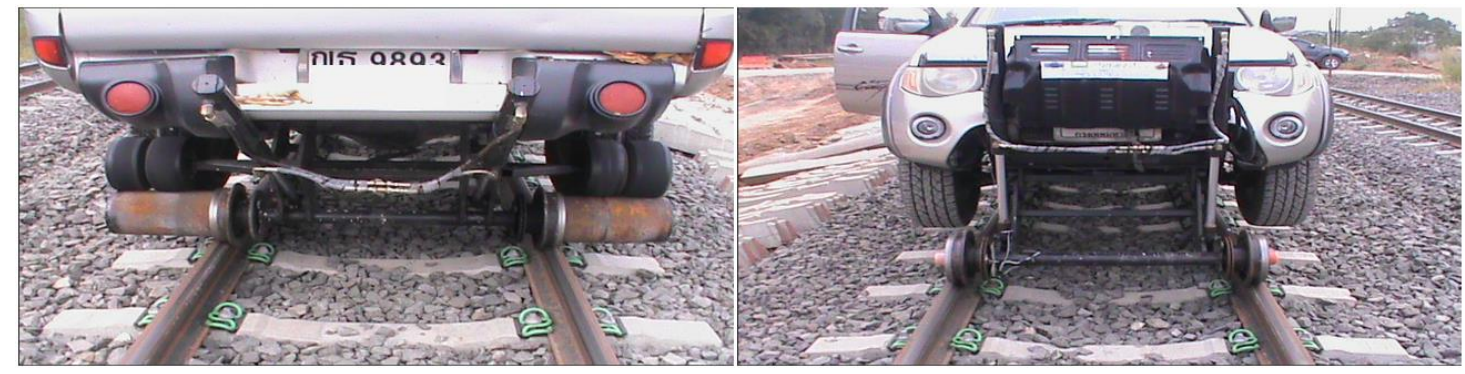

Figure 12. The put down of rear and front train steel wheels on rails

\subsection{Results of vibration signal while run on the rails}

The accelerometer [26] was used to measure the vibration of the chassis body of the vehicle that converts mechanical force to vibration [27] by measuring using the application $G$ sensor Logger [28]. The vibration was measured in the $\mathrm{x}, \mathrm{y}$, and $\mathrm{z}$ axes of the test points is being as. Figure 15 and Figure 16 show that the vibrations signal in the $\mathrm{z}$-axis is very high relative to the other axes. In the $\mathrm{x}$ - and $\mathrm{y}$-axis, vibrations at constant frequencies may be vibrations due to the wheel polling. It's not good enough and in the $\mathrm{z}$-axis, it shows that the rear-drive gear to the steel wheels flicks vigorously, or it could be that the center roller wheel might be touching the tire too much due to the high-lift tire wheel. As the rubber wheels rotate, the power is transmitted through the roller wheels, causing this high $\mathrm{x}$-axis vibration. And it's also possible that the design features of the rubber tire's contact point with friction may be asymmetric in the chassis line. 


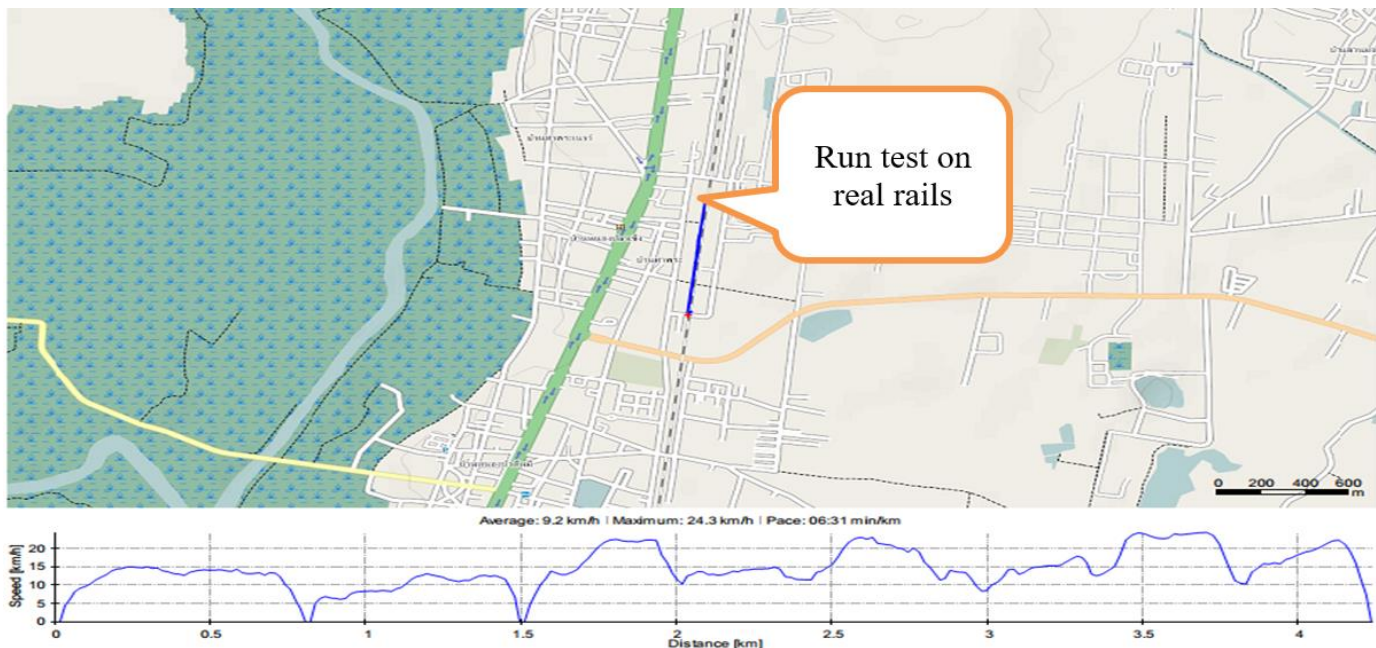

Figure 13. GPS position of the test run on the rails at the Tha-Phra-Khon Kaen station
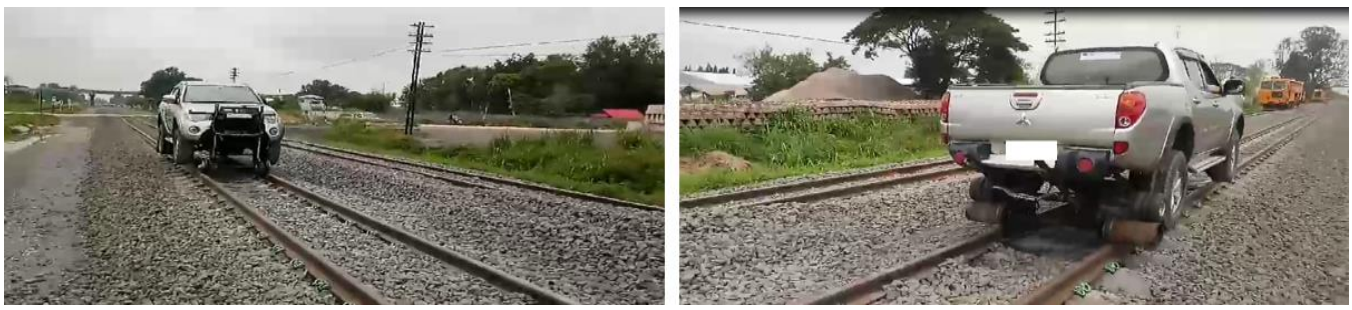

Figure 14. Test run on the rails at Tha-Phra railway station, Khon Kaen province

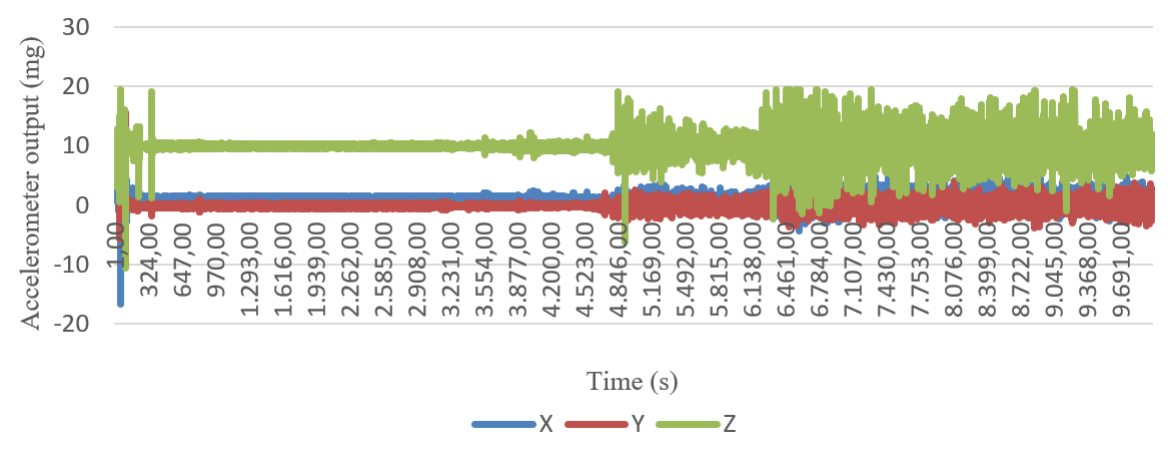

Figure 15. The vibration signal of the rear of the vehicle tested on the rails

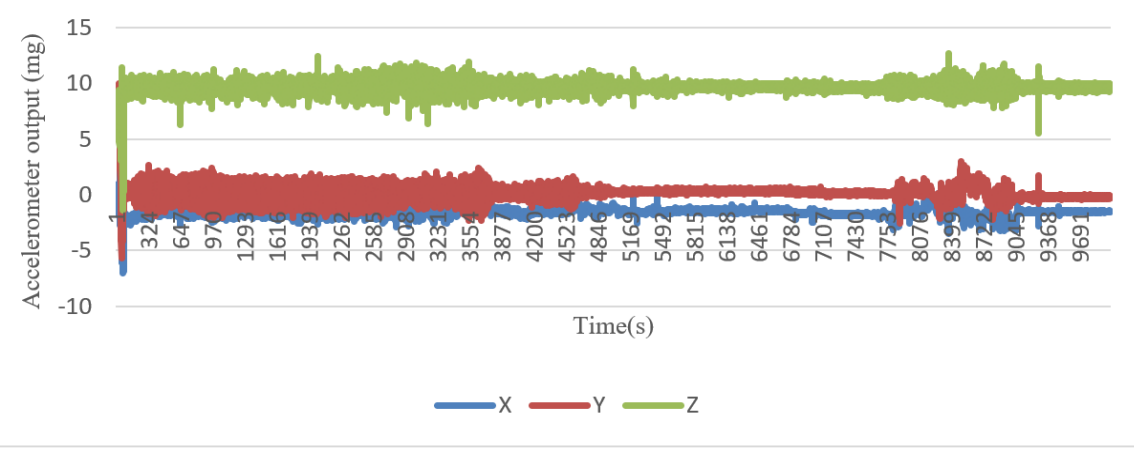

Figure 16. The vibration signal of the interior area of the vehicle tested on the rails 


\section{CONCLUSION}

This research project has proposed the development of a pickup truck modified to add equipment that can make the vehicle run on the road or rails. This vehicle could be useful for rails maintenance or transporting people if a train accident occurs in a remote area that cannot be reached by vehicle. This pickup truck is equipped with an additional weight of about $250 \mathrm{~kg}$. The road test can be driven normally. The test runs on the rails that the speed will not exceed $30 \mathrm{~km} / \mathrm{hr}$. The vehicle runs well and there is some vibration along the front and rear wheels. The prototype vehicle was not designed in terms of both front and rear suspension and could be developed in further research. As for the control system for hoisting steel wheels on the rails, there are two types of designs which are programmable logic controllers and mobile application systems that work well. Placing the front and rear steel wheels on the rails takes about 30 seconds to lift the vehicle. The front and rear, guide train steel wheels assembly are used electric hydraulic pumps driven by dc electric motors that consume a lot of electricity. While in use of this vehicle on rails, the engine should be started. The results of the test running on the rails and showing the results of the vibration signal measurement at a speed of not more than $30 \mathrm{~km} / \mathrm{hr}$. It was found that vibration in the z-axis, which is the key line that can cause the vehicle to derail at high speeds. The transfer of power into the steel wheels with this mechanism is based on the friction of the tire contact area. There may be a flicking of the tire wheels due to the tire wheels when hanging in the lift. The force that holds the axle and wheels with leaf springs and shock absorbers may not be stable enough. Therefore, the vehicle running on the rails should run at a speed of not more than $30 \mathrm{~km} / \mathrm{hr}$.

\section{ACKNOWLEDGEMENTS}

This research was supported by National Science and Technology Development Agency (NSTDA) and Rajamangala University of Technology Isan.

\section{REFERENCES}

[1] S. Xu, C. Bing, X. Hou, and Z. Ma, "Design of an Electric Road-Rail Vehicle," MATEC Web of Conferences 77, 2016, p. 01018, doi: 10.1051/matecconf/20167701018.

[2] M. Ogata, I. Tsutsumi, Y. Shimotsuma, and N. Shiotsu, "Origin of the world's standard gauge of railway is in the interval of wheel ruts of ancient carriages," The International Conference on Business \& Technology Transfers, vol. 3, pp. 98-103, 2006, doi: 10.1299/jsmeicbtt.2006.3.0_98.

[3] S. Koizumi, "Advance in railway vehicle technology and future prospects mainly in relation to bogie," Nippon Steel \& Sumitomo Metal Technical Report, no. 105, pp.11-18, December 2013.

[4] T. Q. Nguyen, "Finite Element Analysis in Automobile Chassis Design," Applied Mechanics and Materials, vol. 889, pp. 461-468, 2019, doi: 10.4028/www.scientific.net/AMM.889.461.

[5] B. Razzaghzadeh and M. Salimi, "Analysis of a Bidirectional DC-DC Converter with High Voltage Gain," Bulletin of Electrical Engineering and Informatics, vol. 4, no. 4, pp. 280-288, December 2015, doi: 10.11591/eei.v4i4.511.

[6] N. Ahmadi and Z. K. Jahromi, "Remote reading of electricity meters using PLC," Bulletin of Electrical Engineering and Informatics, vol. 9, no. 2, pp. 466-472, April 2020, doi: 10.1159/eei.v9i2.1620.

[7] K. E. M. Latha H. Shankar, "Static and Dynamic Analysis of a Car Chassis Using FEA," International Journal of Innovative Research in Science, Engineering and Technology, vol. 6, no. 8, pp. 16421-16431, 2017, doi: 10.15680/IJIRSET.

[8] N. Tulasiram and T. N. Charyulu, "Design and Analysis of Vehicle Chassis Frame," Indian Streams Research Journal, vol. 2, no. 7, August 2012.

[9] M. D. Vijayakumar, C. R. Kannan, S. Manivannan, J. Vairamuthu, S. Tilahun, and P. M. B. Ram, "Finite element analysis of automotive truck chassis," Materials science and engineering, IOP conf. Series, vol. 988, no. 1, p. 012114, 2020.

[10] R. C. Sharma, S. K. Sharma, and S. Palli, "Rail Vehicle Modelling and Simulation using Lagrangian Method," International Journal of Vehicle Structures \& Systems, Chennai, vol. 10, no. 3, pp.188-194, 2018, doi: 10.4273/ijvss.10.3.07.

[11] B. Jagadeep, P. Kiran Kumar, and K. Venkata Subbaiah, "Stress Analysis on Rail Wheel Contact," International Journal of Research in Engineering, Science and Management, vol. 1, no. 5, pp. 47-52, May 2018.

[12] E. Auf, "Basic Electro-Hydraulics," Tetra Pak, Lund, 2018.

[13] J. Parambath, "Relay-Based-Electro-Hydraulic-systems \& Industrial Hydraulic Systems-Theory and Practice," Fluidsys Training Centre, Universal Publishers, 2016.

[14] D. Hagen, D. Padovani, and M. K. Ebbesen, "Study of a Self-Contained Electro-Hydraulic Cylinder Drive," 2018 Global Fluid Power Society PhD Symposium (GFPS), 2018, pp. 1-7, doi: 10.1109/GFPS.2018.8472360.

[15] J. Pančík and P. Maxera, "Control of Hydraulic Pulse System Based on the PLC and State Machine Programming," Designs, vol. 2, no. 4, p. 48, November 2018, doi: 10.20944/preprints201809.0308.v1.

[16] J. Xie, S. Wu, and J. Yuan, "Design of Group Control System of Manipulator Based on PLC," International Core Journal of Engineering, vol. 6, no. 7, pp. 254-260, 2020, doi: 10.6919/ICJE.202007_6(7).0036.

[17] N. A. Hadi et al, "Development of an automatic can crusher using programmable logic controller," International Journal of Electrical and Computer Engineering (IJECE), vol. 9, no. 3, pp. 1795-1804, June 2019, doi: 10.11591/ijece.v9i3.pp1795-1804.

[18] Z. Ding, Y. Li, and Z. Zhang, "Electric hybrid control method of assembly line robot based on programmable logic controller," Thermal Science, vol. 24, no. 3A, pp. 1505-1511, 2020, doi: 10.2298/TSCI190623015D.

[19] T. Mikolajczyk, H. Fuwen, L. Moldovan, A. Bustillo, M. Matuszewski, and K. Nowicki, "Selection of machining parameters with Android application made using MIT App Inventor bookmarks" Procedia Manufacturing, vol. 22, pp. 172-179, 2018, doi: 10.1016/j.promfg.2018.03.027.

[20] E. Jaiswal, Divya C. D., and Bharath T. S., "An Approach to Control a Pneumatic Cylinder Using an Android Application," International Journal of Advanced Research Trends in Engineering and Technology (IJARTET), vol. 2, no. 5, pp. 23-26, May 2015. 
[21] M. D. Albakhait, M. S. Hasan, and A. A. Hajer, "Bluetooth Based Smart Home Automation System using Arduino UNO Microcontroller," Journal of engineering and applied sciences, vol. 14, no. 17, pp. 6325-6357, 2019, doi: 10.36478/jeasci.2019.6352.6357.

[22] N. D. Jayanto and J. Kustija, "Remote desktop system in IoT and HTML 5-based virtual laboratory for HMI (Human Machine Interface) practicum and hydraulic simulation," IOP Conference Series: Materials Science and Engineering, IOP Publishing, vol. 830, no. 4, pp. 1-6, April 2020, doi: 10.1088/1757-899X/830/4/042052.

[23] J. Lee and S. Han, "A study on a configuration of the hydraulic tilting actuator and its experimental evaluations," 2012 12th International Conference on Control, Automation and Systems, 2012, pp. 127-129.

[24] M. S. Ahsan, S. Das, and H. Mobarak, "Android App based Bluetooth controlled Low-cost Cloth Folding Machine," 2020 IEEE Region 10 Symposium (TENSYMP), 2020, pp. 170-173, doi: 10.1109/TENSYMP50017.2020.9231012.

[25] I. Akbar and A. F. Misman, "The Semantics in GPS Based Mobile Applications for Blind Users Navigation Outdoor," International Journal on Perceptive and Cognitive Computing (IJPCC), vol 5, no. 2, pp. 46-51, 2019, doi: 10.31436/ijpcc.v5i2.116.

[26] B. An and Y. Kim, "Improved Crash Detection Algorithm for Vehicle Crash Detection," Journal of the Semiconductor \& Display Technology, vol. 19, no. 3, pp. 93-99, 2020.

[27] Y. Lu, P. Xiang, P. Dong, X. Zhang, and J. Zeng, "Analysis of the effects of vibration modes on fatigue damage in high-speed train bogie frames," Engineering Failure Analysis, vol. 89, pp. 222-241, July 2018, doi: 10.1016/j.engfailanal.2018.02.025.

[28] J. King, "Speedometer app videos to provide real-world velocity-time graph data 1: rail travel," Physics Education, vol. 53, no. 2, p. 023006, 2018, doi: 10.1088/1361-6552/aa9d34.

\section{BIOGRAPHIES OF AUTHORS}

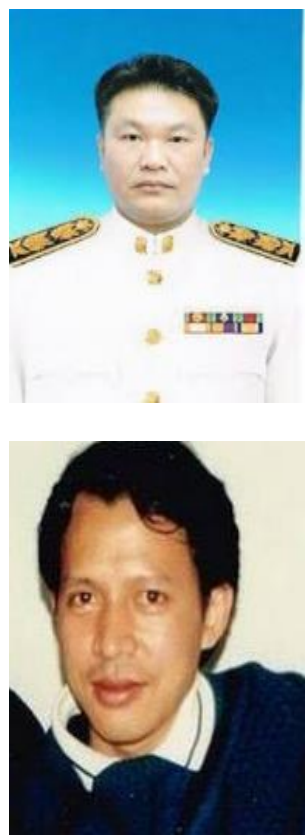

Viroch Sukontanakarn (iD $\mathrm{SD}$ S $\mathrm{P}$ is an Assit.Prof at Field of Mechatronics Engineering at the Rajamangala University of Technology Isan Khonkaen Campus, Thailand. He received M. Eng in Electric Power System Management and D. Eng in Mechatronics from Asian Institute of Technology. His research interests are power electronics, electrical power systems, microcontrollers, robotics, programmable logic controller, and electric motor drive. He can be contacted at email: viroch.su@rmuti.ac.th.

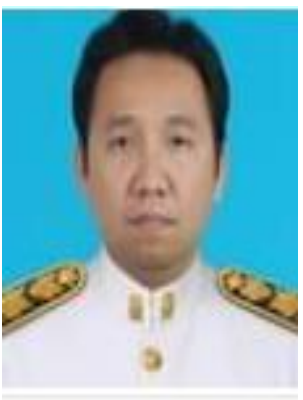

Boonlit Pongsatitpat (D) SC $\mathrm{P}$ is a Lecturer at Field of Mechatronics Engineering at the Rajamangala University of Technology Isan Khon kaen Campus, Thailand. He received M. Eng.Sc in Electrical Power from The Suranaree University of Technology. His research interests are microcontrollers, mechanical systems, and power electronics. He can be contacted at email: boonlit@rmuti.ac.th. 